\title{
Landscape Painting
}

\author{
Kate Sandilands
}

Joyce Nelson, Sign Crimes/Road Kill: From Mediascape to Landscape (Toronto, Between the Lines 1992).

Andrew Wilson, The Culture of Nature: North American Landscape from Disney to the Exxon Valdez (Toronto, Between the Lines 1991).

As Raymond Williams wrote some time ago, "the idea of nature contains, though often unnoticed, an extraordinary amount of human history." At the same time as the idea marks a series of radically different, and historically changing, usages, relations and meanings, it has also come to represent some basic quality, some underlying continuity that differentiates the epiphenomenal from the essential in humanity's vision of itself and the world. Thus, the movement between the "nature" of something and the something called "nature" shows a social order in the throes of self-definition: the tension between the production of an "essence," a sense of a historical trajectory, and the synchronic proliferation of plural meanings, in the working-out of "nature."

Joyce Nelson and Andrew Wilson both capture this tension well; each shows the constitution of nature through the multiple, conflicting, and often destructive discourses of modernity and postmodernity. Indeed, they both go a long way toward showing just how much human history is contained in the idea of "nature." In an era marked by "ecological crisis," such investigations would seem crucial indeed. But these books are not panic texts, not works of social inquiry parroting the voices of "hard" science on environmental apocalypse. They are, instead, works which show the tensions and contradictions of North Americans's relations to "nature," something that all too many contemporary writings of an environmentalist vein overlook in their singular condemnation of the more destructive elements of western social life.

Both books are at once "epics" and "anthologies." Each tells of the particular (geographic, historical) journey of its author; in her or his own working-out of relations to "nature," the reader is led to embark on a similar quest. At the same time as there is a pervasive sense of movement, however, the stories are told as a series of "snapshots," or, more accurately, "landscapes," moments of social/natural life in which the multiple meanings of each term are enunciated. As Wilson describes, "in the broadest sense of the term, landscape is a way of seeing the world and imagining our relationship[s] to nature. It is something we think, do, and make as a social collective" (14). Thus, each "landscape" reveals a particular moment of the signification and construction of "nature," but each is, at the same time, always already part of some broader, common journey.

Nelson's book shows a journey toward "landscape." Sign Crimes/Road Kill is a collection of previously published essays written between 1980 and 1991. Readers acquainted with her writings will know Nelson to be a sharp critic of the relations between media, politics, and the corporate world; ${ }^{2}$ while this sensibility remains

1 Raymond Williams, "The Idea of Nature," in Materialism and Culture: Selected Essays (London 1980), 67.

2 See for example, Joyce Nelson, Sultans of Sleeze: Public Relations and the Media (Toronto, 1989). 
strong throughout the book, what becomes increasingly evident in her movement from "mediascape" to "mindscape" to "landscape" is a realization that human relations to nature are bound up in the same technocratic, homogenizing webs as the cultural and political events of her previous investigations.

Nelson explains her movement to "landscape" this way:

I've been investigating and writing about sign crimes for fifteen years, but only relatively recently has roadkill caught my attention. Now it seems inevitable to me that the environmental degradation all around us would - of course! — be the likely outcome of a mass-media monoculture bent on destroying diversity worldwide. You reap what you sow, and this millennial century has sown devastation as our legacy

Thus, one of the threads running through this collection (and there are others) is that the destruction of biodiversity so often lamented by environmentalists is part of a simultaneous destruction of cultural heterogeneity. Nelson's journey toward "landscape" is thus one which reveals the erosion of the land itself, not just physically but culturally, in North American social life. Mickey Mouse thus replaces wild animals, both literally and figuratively; videotapes replace tactile mother/child interactions in the lifeworld of newborn infants; the mountain at Canada's Wonderland (which Nelson describes, in one of my favourite quotations, as "a magnificent pimple on the smiling face of a bureaucrat") (34) suffocates not only rich agricultural land, but the possibility of diverse "organic" cultural experiences.

Her location of North American experiences of "nature" in this massified context is an important analytic move: we can't think of "culture" as manifesting one logic, "nature" as operating by another. Rather, the two are inextricably linked, as Nelson's investigations of Canada/U.S. water export schemes, plutonium flights over the Arctic, corporate "ecobabble," and agrichemicals show most forcefully: in order to show the possibility for alternative relations to nature, we need to think about reorienting "culture." That reorientation includes a critical analysis of the institutions that directly affect "nature," but it also includes a rethinking of how high technology, mass culture and bureaucratic rhetoric create the "nature" that North Americans experience. To Nelson, then, it seems that showing the possibility of proliferation the fostering of diverse, "organic" relations to nature in the face of mass image - is, in fact, a subversive, environmentalist action through which any hope for wholeness must proceed.

Nelson is a talented sign crimes detective; this collection showcases some of her best investigations, all told in a style that highlights the ironies and contradictions of media, policy, and political manoeuvring. She wades deftly through the mires of political doublespeak and bureaucratic obfuscation to tell the stories that don't get told, to unwind the tangled threads leading to public "events." To speak the unspoken: this is Nelson's agenda. Unfortunately, the collection does not leave the reader with an equally articulate sense of how these "unspoken" elements might be connected, might be collected as part of a transformative project. Perhaps ironically, the piece "Speaking the Unspeakable: Understanding Ecofeminism" is the weakest essay in the book; as the only example Nelson gives us of a landscape of "resistance," the essay lacks the critical depth of her other moments of inquiry into social constructions of media and politics.

"Solutions" are, of course, a tall order; nonetheless, it would have been helpful for Nelson to have drawn together some of her critical insights into cultural politics to orient the "proliferation" she implicitly advocates. She writes in the introduction: 
Sign Crimes/Road Kill is what the critics might call an "uneven" collection. But I wanted it to be uneven. Life is uneven. It's also quirky and idiosyncratic (the book, life), but I wonder, is it (the book) weird enough? (9)

The picture she paints of the collisions between "nature" and "culture" certainly show just how "weird" life may be - the book is, by the way, as unapologetically "uneven" as she claims - but the version of ecofeminist resistance she proposes explicitly (a form which, it could be argued, might contradict her implicit project of proliferation) is certainly not "weird" enough to orient the task of transformation. Perhaps most importantly, she never really shows a moment where the collisions between nature and culture might be celebrated; despite the careful playfulness, or perhaps hopeful irony, of her discussions of media and politics, as soon as "nature" enters into the picture, "culture" tends to get reduced to its moment of destruction.

Wilson's The Culture of Nature is, in many senses, weirder; at the same time, it contains a more coherent, more focused, political project. Like Sign Crimes/Road Kill, the book collects a series of different landscapes and ties them together as part of a journey (owing to the fact that The Culture of Nature is a "book" and not an anthology, the ride is a little less bumpy); unlike Nelson's, however, Wilson's is clearly a self-conscious journey through landscape, rather than toward it. As a result, the book is able to move beyond the moment of implicit proliferation toward a sense of collection and movement, and is able to resist the temptation to bifurcate "nature" from "culture," and "good" from "bad."

Wilson begins by suggesting that experiences of nature are always mediated by culture; he argues that "confronting the many conflicting ideas of nature at large today will help us to understand the kinds of land development that in the past fifty years have so altered our towns and cities, farms and wildlands." (13) To Wilson, a politics of "landscape" can never be simply one of preservation of "nature" (in fact, he shows quite forcefully just how much "culture" goes into the construction - culturally and physically - of so-called "wild" spaces). Rather, he suggests that the "landscapes" he describes are always suffused with a sense of human self-realization, human culture, and human responsibility for their construction and reconstruction. All of these moments are described with a profound sense of enjoyment; Wilson shows that an ecological politics responsive to "culture" necessarily spends some time in celebrating the paradoxes of social life, as they are worked through nature.

Wilson begins his journey by having the reader recognize her or himself as a tourist; the largely North American readers of his book are, thus, set up to take an analytic road-trip with him. We are spectators of the social construction of nature; armed with this guide book, we are shown how to identify species, landmarks, vistas, and cultural "artifacts." But the journey is not to the "wild" as we generally understand it; it is through the familiar landscapes of scenic drives, nature interpretation trails, Disney wildlife documentaries, theme parks and world fairs, malls, safari parks, and real estate developments. These landscapes, to Wilson, are the places through which most North Americans "know" nature: as already inescapably social, and as already part of how social life is constituted.

The self-consciousness of the journey is truly delightful; at the same time as the reader has no choice but to take part in the common sense of the landscapes Wilson describes, $\mathrm{s} / \mathrm{he}$ is constantly led to understand how that common sense is possible, how it is contingent on particular policies, particular versions of "landscape design." We "know" Disney World, Mutual of Omaha's Wild Kingdom, the West Edmonton Mall, and the suburban lawn, yet in Wilson's book we are led to locate that knowledge 
in some sort of context, in some sort of pattern which reveals the omnipresence of "nature" in various guises.

The "nature/culture" wall is thoroughly toppled in this book, but not in a way that has us simply mourn the process as an inevitable result of cultural invasion, or as a function of some dark, "human" quality of domination. Rather, Wilson suggests that the understanding of nature as part of culture, and vice versa - the moment where culture and nature intertwine - is the starting point for a liberatory ecological project. It is at this point that we have choices: the environmental movement needs to take part in the reorientation of discourses of nature, not simply to lament the erosion of its sublime, "pure" state. Likewise, important though the recognition of plurality may be, the reconstruction of relations of "connection" are crucial.

The moment of "deadly seriousness" comes in the last chapter, where Wilson discusses such topics as hydro megaprojects, nuclear power plants, and strip mining. The first time I read the book, I was dismayed that Wilson had not extended his analytic enjoyment, his sense of "celebrating" the paradoxes, into these landscapes, as if they were too serious to merit ironic treatment. While I still feel that this last chapter doesn't work as well as, for example, Wilson's treatment of Epcot centre which is, in many respects, just as frightening and potentially apocalyptic as a nuclear power plant - it is through these landscapes that Wilson shows the ways in which a variety of others are connected: by capital. In this chapter, the journey comes full-circle: we began by recognizing ourselves as tourists, and now arrive back at the relations which have made this position possible. The landscapes are not isolated; they are connected through a political and economic web just as massive, and just as dangerous, as the hydro wires of the Tennessee Valley Authority, and we, too, are caught in them. The point is, then, to transform the connections themselves; "without broad social empowerment and true democratic institutions," Wilson writes, "our connections to the natural world will continue to be characterized by greed and exploitation, the very values so rampant in our social lives." (16)

Like Nelson, Wilson celebrates the moment of proliferation, the necessity for the rediscovery or creation of a variety of possible experiences of "nature," as part of a political project oriented toward an eventual "wholeness." varied "connections" to nature are necessary to the future. Unlike Nelson, he is careful to show that the places of knowing nature from which we necessarily begin are not, nor can they be seen to be, thoroughly "corrupt": the "connections" that we have can never be seen as simply alienated, simply aspects of destructive discourses of nature. It is not enough to "oppose" culture en route to knowing nature; we already know it, and can't forget that we are always already intertwined in nature in a variety of ways. The task of transformation thus begins in a celebration of that knowledge, for all its problems, as a knowledge of the sublime "nature" itself. To quote Williams again, "we need and are perhaps beginning to find different ideas, different feelings, if we are to know nature as varied and variable nature, as the changing conditions of the human world." Nelson's and Wilson's landscapes recognize this need, and show the tension between a sublime moment of "nature" and its variable location in a proliferation of cultural contexts. But the future of nature cannot be formed without recognizing that there is movement, "connection," between the two moments. 